\title{
Carbon isotopes of essential amino acids highlight greater contribution of far-field vs near-field subsidies to predators on oceanic coral reefs
}

\author{
Christina Skinner ${ }^{1}$, Aileen C Mill ${ }^{1}$, Steven Newman ${ }^{2}$, Yiou Zhu ${ }^{1}$, Alison Kuhl ${ }^{3}$, and \\ Nicholas Polunin ${ }^{1}$ \\ ${ }^{1}$ Newcastle University School of Natural and Environmental Sciences \\ ${ }^{2}$ Banyan Tree Marine Lab \\ ${ }^{3}$ University of Bristol
}

May 5, 2020

\begin{abstract}
Reef predators are partly sustained by oceanic production sources, but the pathways through which this occurs remain poorly understood. Studies exploring reef-pelagic linkages have used bulk stable isotopes, yet these have limited power to discriminate between major source types. We used $\delta 13 \mathrm{C}$ values of essential amino acids ( $\delta 13 \mathrm{CEAA}$ ), which can better resolve different modes of carbon acquisition, to trace the origin of the carbon sources sustaining reef predator biomass in the Maldives. White muscle tissue was sampled from four key fishery target groupers and eight primary consumer species (representing six energy pathways). Primary consumer 613CEAA values separated into four distinct clusters: 1) algae/detritus, 2) coral, 3) reef plankton, and 4) pelagic plankton. Bayesian stable isotope mixing models identified pelagic plankton as primarily sustaining all four groupers across the atoll, indicating that oceanic nutrients are available throughout and that these reefs may be more resilient to bleaching-induced loss of live coral.
\end{abstract}

\section{Introduction}

Coral reefs are traditionally considered to be productive hotspots in oligotrophic deserts (Darwin 1842) but their food webs are complex (Bierwagen et al. 2018) and the mechanisms through which they maintain exceptionally high diversity and biomass remain poorly understood. There is increasing evidence that oceanic production sources are fundamentally important in sustaining reef fish communities (McCauley et al. 2012; Frisch et al. 2014; Frisch et al. 2016; Matley et al. 2018; Skinner et al. 2019), particularly on degraded forereef slopes (Morais \& Bellwood 2019).

Bulk stable isotope data have helped elucidate these reef-pelagic linkages but they lack resolution, for example co-occurring sources may not be isotopically distinct (Skinner et al. 2019; Whitemanet al. 2019), preventing accurate separation. The isotopic data that characterise food-web baselines will also vary with environmental conditions (Boecklen et al. 2011; Larsen et al. 2013), requiring robust sampling of dietary sources to compare data across spatial and temporal scales (Hadwen et al. 2010; Liew et al. 2019). Furthermore, as macromolecules are often not directly routed to consumer tissue, there is a trophic fractionation factor between consumer and diet (DeNiro \& Epstein 1978) which varies substantially among species (Wyatt et al. 2010).

The profiling of specific biochemical compounds, such as amino acids is now feasible (compound-specific stable isotope analysis; CSIA). As the building blocks of proteins, amino acids can be categorised as: essential 
(EAA, organisms cannot synthesize them de novo ), conditionally essential (de novo synthesis requires specific physiological conditions), or non-essential (organism can synthesise them de novo ) (Whiteman et al. 2019). The $\delta{ }^{13} \mathrm{C}$ values of individual amino acids ("13 C fingerprints") help reveal modes of carbon acquisition; the $\delta{ }^{13} \mathrm{C}$ derives from the specific synthesis pathways involved (Larsen et al. 2009). As organisms cannot synthesize EAAs de novo, fractionation between diet and consumer is minimal and the ${ }^{13} \mathrm{C}$ values of consumer amino acids represent the primary producer sources of carbon (McMahon et al. 2010). Even when bulk values vary, $\delta{ }^{13} \mathrm{C}$ primary producer fingerprints are robust to differing growth and environmental conditions (Vokhshoori et al. 2014; Larsen et al. 2015; McMahon et al. 2015a) and broad patterns are consistent across studies and labs (Liew et al. 2019).

In both terrestrial and aquatic systems (Larsen et al. 2009; Larsen et al. 2013; McMahon et al. 2015a; McMahon et al. 2016), EAAs help distinguish primary producers with different carbon origins; amino acid $\delta^{13} \mathrm{C}$ values of aquatic types of primary producers are especially distinct (Arthuret al. 2014; Wang et al. 2018). Bayesian mixing models using bulk stable isotope data indicate that reef predators are predominantly sustained by planktonic production sources, even inside atoll lagoons (Skinner et al. 2019). However, due to the methodological constraints associated with the lower resolution of bulk stable isotopes and the inability to separate isotopically similar planktonic sources, the origin of this pelagic production remains unclear. Phytoplankton are primarily composed of protein (Nguyen \& Harvey 1997; Hedges et al. 2002) and different plankton communities have been separated using $\delta^{13} \mathrm{C}$ amino acid values (McMahon et al. 2015a). This suggests that planktonic sources with different origins may have distinct $\delta{ }^{13} \mathrm{C}$ EAA values, providing additional resolution to disentangle the sources of planktonic carbon sustaining predators on reefs.

Bulk stable isotope data vary in their resolution of relationships between body size and trophic ecology (Layman et al. 2005; Ouet al. 2017; Dalponti et al. 2018). Organisms may change their diets over time; larger body size allows a wider range of prey to be exploited (Scharf et al. 2000), which would lead to changes in stable isotope values. Few studies to date (e.g. McMahon et al.2012; Vane et al. 2018) have used the greater power of EAA $\delta{ }^{13} \mathrm{C}$ data to investigate how resource use might change with increasing body size and how this might affect isotope values. To determine how consumers will respond to environmental change and fluctuations in resource availability, knowledge of their resource use and how it varies with increasing body size or spatially is needed.

Here, $\delta{ }^{13} \mathrm{C}$ values of EAAs were used to help trace the origin of the organic carbon sustaining predator biomass across an oceanic atoll. The main questions addressed were: 1) Do $\delta{ }^{13} \mathrm{C}_{\mathrm{EAA}}$ values vary spatially or with body size? 2) Do primary consumers have distinct $\delta{ }^{13} \mathrm{C}_{\mathrm{EAA}}$ values? 3) If so, are there differences in predator planktonic resource usage spatially?

\section{Material and methods}

Tissue sampling procedure

Sampling occurred across both inner and outer atoll areas of North Malé atoll, Maldives (Figure S1). All tissue samples were collected during the NE monsoonal period (January - April 2017 and December 2018) to avoid any seasonal fluctuations in production sources and their signatures.

Groupers were chosen as representative reef predators as they are relatively site-attached, while other reef predators, e.g. snappers, have larger home ranges involving long-distance movements (Sluka \& Reichenbach 1995; Farmer \& Ault 2011; Green et al. 2015). Four grouper species were selected as they were the most abundant upper trophic level (assumed TL [?] 4) groupers in both inner and outer atoll (Skinner et al. 2019), reach a range of sizes allowing for comparison of resource use at different lengths, and are a key component of the local reef fishery (Sattar et al. 2014). Samples of white dorsal muscle tissue ( $\sim \mathrm{g}$ wet mass) were removed fromAethaloperca rogaa (redmouth), Anyperodon leucogrammicus(slender), Cephalopholis argus (peacock), and Cephalopholis miniata (coral hind). Fish were sampled from both inner and outer atoll using a pole spear and across a large size range $(\sim 150 \mathrm{~mm})$ relative to their maximum body size. Care was taken not to sample juveniles $(<15 \mathrm{~cm})$ to control for dietary changes related to ontogeny. All tissue sampling was carried out in compliance with UK Home Office Scientific Procedures (Animals) Act Requirements. 
Primary consumer species were used to represent food sources. Six energy pathways were identified: 1) benthic algae: powderblue surgeonfish, Acanthurus leucosternon (samples $\mathrm{n}=7$ inner, 6 outer) (Robertsonet al. 1979); 2) detritus: bristletooth surgeonfish,Ctenochaetus striatus ( $\mathrm{n}=7$ inner, 6 outer) (McMahonet al. 2016); 3) coral: scrawled butterflyfish, Chaetodon meyeri ( $\mathrm{n}=3$ inner, 6 outer) (Sano 1989), 4) diurnal reef plankton: variable-lined fusilier, Caesio varilineata $(\mathrm{n}=2$ inner, 3 outer $)$, yellowback fusilier, Caesio xanthonota, ( $\mathrm{n}=1$ inner, 7 outer) (Bellwood 1988; Hamner et al. 1988; Russ et al.2017); 5) nocturnal reef plankton: lattice soldierfish,Myripristis violacea $(\mathrm{n}=6$ inner, 6 outer) (Hobson 1991); 6) pelagic plankton: mackerel scad, Decapterus macarellus ( $\mathrm{n}=7$ inner) (Smith-Vaniz 1995), Indian Ocean squid, Uroteuthis duvauceli ( $\mathrm{n}=7$ outer) (Islam et al. 2018).

Amino acid (AA) derivatisation and stable isotope analysis

Muscle tissue was oven dried at 50degC for 48 hours and then ground to a fine powder using a pestle and mortar. N-Acetyl Isopropyl Ester (NAIP) derivatives of amino acids were prepared by following the protocol described by Corr et al. (2007). Briefly, this entailed hydrolysis of individual aliquots (1.5mg) of dried powdered muscle tissue with internal standard norleucine $(400 \mu \mathrm{g} / \mathrm{mL})$, followed by isolation of the amino acid fraction using ion exchange chromatography with Dowex ${ }^{\circledR}$ 50WX8 hydrogen form resin (200 - 400 mesh). Isopropyl esters were prepared by addition of a 4:1 mixture of isopropanol and acetyl chloride and heating for 1 hour $\left(100^{\circ} \mathrm{C}\right)$. After removal of excess reagents by re-dissolving in dichloromethane then drying with $\mathrm{N}_{2}\left(40^{\circ} \mathrm{C}\right)$, acetylation was achieved by adding a mixture of acetone:triethylamine:acetic anhydride (5:2:1) and heating for 10 minutes $\left(60^{\circ} \mathrm{C}\right)$. Isolation of the NAIP derivatives was achieved using liquid-liquid separation with $\mathrm{NaCl}$ solution (saturated) and ethyl acetate. All organic phases were combined and dried under a very gentle stream of $\mathrm{N}_{2}$ (room temperature). Any residual water was removed with two successive $1 \mathrm{ml}$ aliquots of DCM and evaporated under a very gentle stream of $\mathrm{N}_{2}$ (ice bath). Samples were then stored in a freezer until they could be screened.

For screening, the derivatised AAs were resuspended in ethyl acetate and analysed using gas chromatography with an Agilent 7890 gas chromatograph with flame ionization detection (GC/FID), fitted with a DB-35 column 30m x 0.32mm x 0.5um (Agilent), and an Agilent G4513A autosampler (Agilent Technologies, Santa Clara, CA, USA). The GC oven temperature was set to the following program: $70^{\circ} \mathrm{C}$ (hold 2 minutes) to $150^{\circ} \mathrm{C}$ at $15^{\circ} \mathrm{C} \mathrm{min}{ }^{-1}$, then to $210^{\circ} \mathrm{C}$ at $2^{\circ} \mathrm{C} \mathrm{min}-1$, then to $270^{\circ} \mathrm{C}$ at $8^{\circ} \mathrm{C} \mathrm{min}{ }^{-1}$. The injection mode was Cold on Column (COC) and the injection volume was $1 \mu \mathrm{l}$ with helium carrier gas at a flow rate of $2.00 \mathrm{ml} / \mathrm{minute}$.

The $\delta{ }^{13} \mathrm{C}$ isotopic compositions of the AAs were analysed using a GC/IRMS. A Thermo Scientific (Bremen, Germany) Delta V Plus isotope-ratio mass spectrometer (IRMS) was fitted with a Trace GC Ultra Oven, GC Isolink, and a ConFlo 4 for interface. The GC was fitted with a DB-35 column $30 \mathrm{~m} \times 0.32 \mathrm{~mm} \times 0.5 \mu \mathrm{m}$ (Agilent). The oven was set as follows: $40^{\circ} \mathrm{C}$ (hold 5 minutes) to $120^{\circ} \mathrm{C}$ at $15^{\circ} \mathrm{C} \mathrm{min}{ }^{-1}$, then to $180^{\circ} \mathrm{C}$ at $3^{\circ} \mathrm{C}$ $\min ^{-1}$, then to $210^{\circ} \mathrm{C}$ at $1.5^{\circ} \mathrm{C} \mathrm{min}^{-1}$, then to $270^{\circ} \mathrm{C}$ at $5^{\circ} \mathrm{C}$ (hold 7 minutes).

Pulses of reference gas $\left(\mathrm{CO}_{2}\right)$ were introduced into the IRMS instrument during the analysis giving rise to peaks with known $\delta{ }^{13} \mathrm{C}$ values $\left({ }^{13} \mathrm{C}:{ }^{12} \mathrm{C}\right.$ ratio relative to Pee Dee Belemnite). These reference pulses were used to calculate the analyte peaks in each chromatogram. Identification of the derivatised amino acids was achieved by matching the peak elution times with those from a mixed amino acid standard (derivatised) containing alanine [Ala], glycine [Gly], valine [Val], leucine [Leu], norleucine [Nle], threonine [Thr], serine [Ser], proline [Pro], aspartic acid [Asp], glutamic acid [Glu], hydroxyproline [Hyd], phenylalanine [Phe], lysine [Lys] and tyrosine [Tyr].

To account for the change in measured values arising from the addition of carbon atoms during the derivatisation process, a correction factor was determined for each amino acid (Table S1). The correction factor calculation was:

1) $\frac{((\mathrm{cd} \times \text { measured value of standard })-(\text { c x underivatised } 13 C \text { value }))}{d}$

where $c$ is the number of carbon atoms in the amino acid, $d$ is the number of carbons added during the derivatisation process, and $c d$ is the total number of carbon atoms in the derivative group. The correction 
factor for each amino acid was then applied to the raw measured values of the samples using the following equation:

$2) \frac{((\mathrm{cd} \times \text { measured value of standard })-(\text { d } x \text { underivatised } 13 C \text { value })}{c}$

All samples were derivatised at Newcastle University, UK, and all GC/FID work and GC/IRMS work was carried out at the Bristol Node of the NERC Life Sciences Mass Spectrometry Facility, UK. All primary consumer samples (except for the pelagic primary consumers D. macarellusand $U$. duvauceli ) were derivatised and analysed in 2018, while all predators and the pelagic primary consumers were derivatised and analysed in 2019 (Table S1).

Data analysis

Isotopic signatures were derived from the five EAAs: leucine (Leu), lysine (Lys), phenylalanine (Phe), threonine (Thr), and valine (Val). Stable isotope ratios are reported using the delta $(\delta)$ notation with measured values expressed in per mil $\left(\left[\left(\mathrm{R}_{\text {sample }}-\mathrm{R}_{\text {standard }}\right) / \mathrm{R}_{\text {standard }}\right]\right.$ and $R$ is the ratio of heavy to light isotope (e.g. ${ }^{13} \mathrm{C} /{ }^{12} \mathrm{C}$ ). Analyses were carried out in R 3.5.2 (R Core Team 2017) interfaced with RStudio 1.1.463 (RStudio Team 2012).

Essential amino acid $\delta{ }^{13} \mathrm{C}$ values were normalised to their respective sample means (denoted as $\delta{ }^{13} \mathrm{C}_{\mathrm{EAAn}}$ ). For each sample, the mean value of all five EAAs was calculated and then subtracted from the absolute EAA $\delta{ }^{13} \mathrm{C}$ values (denoted as $\delta{ }^{13} \mathrm{C}_{\mathrm{EAAa}}$ ). Normalising the individual $\delta{ }^{13} \mathrm{C}_{\mathrm{EAA}}$ values to the mean removes natural variability in $\delta^{13} \mathrm{C}$ values of the individual amino acids arising from differing environmental (Larsen et al. 2013; Larsen et al. 2015; McMahon et al. 2015a), laboratory or study conditions (Liewet al. 2019). Using this method, trends in ${ }^{13} \mathrm{C}$ fingerprints are consistent and data across studies are compatible, allowing the major carbon sources of the predators to be investigated.

As groupers were sampled during two different time periods, differences in their $\delta{ }^{13} \mathrm{C}_{\text {EAAn }}$ values were investigated using linear mixed effects models with the $\mathrm{R}$ package lme4 (Bates et al. 2015). Separate models were run for groupers in each atoll area (inner/outer), with the $\delta{ }^{13} \mathrm{C}_{\mathrm{EAAn}}$ value as the response variable, sampling year as a fixed effect and grouper species as a random effect. Following this, linear mixed effects models were run to investigate spatial and body size effects on grouper $\delta{ }^{13} \mathrm{C}_{\mathrm{EAAn}}$ values. The $\delta{ }^{13} \mathrm{C}_{\mathrm{EAAn}}$ value was the response variable with grouper species as a random effect and area (inner/outer) and body size $(\mathrm{mm})$ as fixed effects. All model assumptions were checked by plotting the model residuals using histograms and qqplots, and plotting residuals vs fitted values. Wald tests were used to determine significant effects.

Primary consumers were collected from both inner and outer atoll so spatial differences in their $\delta{ }^{13} \mathrm{C}_{\mathrm{EAAn}}$ values were investigated using two sample t-tests. Where two primary consumer species were collected to represent the same food source, two sample t-tests were used to determine whether there were any differences in their $\delta{ }^{13} \mathrm{C}_{\mathrm{EAAn}}$ values. When data did not conform to normality, a non-parametric Mann-WhitneyWilcoxon test was used instead.

Multivariate signatures of the $\delta{ }^{13} \mathrm{C}_{\text {EAAn }}$ values were visualised with principal component analysis (PCA) for the a) groupers, b) primary consumers, and c) groupers and primary consumers using the covariance matrices.

To quantify the contribution of the different food sources to the four grouper species in both inner and outer atoll, a Bayesian stable isotope mixing model was run for each species using the MixSIAR package (Stock \& Semmens 2016a). Primary consumer $\delta{ }^{13} \mathrm{C}_{\mathrm{EAAn}}$ values were separated into representative source groups using k-medoids clustering analysis based on the PAM (partitioning around medoids) algorithm (Kaufman \& Rousseeuw 1990). A medoid is a point in the cluster for which the average dissimilarity between it and all the other points in the cluster is minimal. K-medoids clustering is thus more sensitive to outliers than k-means clustering, which uses the mean of points in the cluster. Clustering was carried out using the cluster package (Maechler et al. 2018) and the factoextra package (Kassambara \& Mundt 2017). The optimal number of clusters was determined using the gap statistic which compares output values of clustering with different numbers of groups to output values from clustering under a reference null distribution of the data (Tibshirani 
et al. 2001). The optimal number of clusters is that with the largest gap statistic, meaning the clustering structure is far from a random distribution of points. Mean and s.d. values were calculated for each cluster to represent source means in the mixing models.

The trophic discrimination factor was set to $0.1 \pm 1.0 \%$ as essential AAs undergo minimal fractionation up the food chain (McMahon et al. 2016). A larger standard deviation value was included to provide the model with additional parameter space. Consumer data were individual grouper $\delta^{13} \mathrm{C}_{\text {EAAn }}$ values. For each model, area (inner/outer) was included as a fixed factor and body size ( $\mathrm{mm}$ ) was included as a continuous variable. Each model was run with process $\mathrm{x}$ residual error terms to incorporate any variation in consumer digestibility or variation related to the sampling process (Stock \& Semmens 2016b). Model MCMC parameters were set to short ( chain length $=50000$, burn $=25000$, thin $=25$, chains $=3$ ). The models were considered converged when no variables had a Gelman-Rubin diagnostic $>1.05$ and based on the Geweke diagnostic less than $5 \%$ of the variables were outside the $95 \%$ CI. Differences in the relative contribution of the dominant food source to groupers between atoll areas was tested for using a two-sample t-test.

\section{Results}

In total, $\delta{ }^{13} \mathrm{C}_{\text {EAAn }}$ values from 72 samples of four species of grouper and 67 samples of eight primary consumer species from both inner and outer atoll were analysed (Table 1). The range in Thr and $\mathrm{Phe} \delta{ }^{13} \mathrm{C}_{\mathrm{n}}$ values was greatest (12.86 and 12.07 respectively), followed by Leu (6.45), Val (6.43) and Lys (6.37).

Groupers in the inner atoll did not differ significantly in any of the $\delta{ }^{13} \mathrm{C}_{\mathrm{EAAn}}$ values between sampling years (Table S2). Among the outer atoll groupers, only the Val ${ }^{13} \mathrm{C}_{\mathrm{n}}$ differed significantly between sampling years; all groupers from both sampling years were combined for all subsequent analyses. Atoll area and body size had no significant effect on any of the grouper ${ }^{13} \mathrm{C}_{\mathrm{EAAn}}$ values (Table 2).

None of the $\delta{ }^{13} \mathrm{C}_{\mathrm{EAAn}}$ values differed between inner and outer atoll for Acanthurus leucosternon, Chaetodon meyeri or Myripristis violacea(t-test or Mann-Whitney-Wilcoxon test, $\mathrm{p}>0.05$ ) (Table S3). For each of these species all samples from both areas were combined and plotted as one group. The $\mathrm{Phe} \delta{ }^{13} \mathrm{C}_{\mathrm{n}}$ values ofCtenochaetus striatus differed significantly between areas (Mann-Whitney-Wilcoxon test, $W=3, \mathrm{p}=$ $0.02)$ but the other $\delta{ }^{13} \mathrm{C}_{\text {EAAn }}$ values did not (Table S3) so this species was not combined. The caesionids Caesio varilineata and C. xanthonota showed differences in the $\delta{ }^{13} \mathrm{C}_{\mathrm{n}}$ values of $\mathrm{Phe}(\mathrm{t}$-test, $\mathrm{t}=2.62$, $\mathrm{df}=$ $10.78, \mathrm{p}=0.02)$ and Val (t-test, $\mathrm{t}=-2.43, \mathrm{df}=8.67, \mathrm{p}=0.04)$ so these two species were not combined (Table S3). None of the $\delta{ }^{13} \mathrm{C}_{\mathrm{EAAn}}$ values distinguished the two pelagic consumers Decapterus macarellus and Uroteuthis duvauceli (two-sample $t$-test, $\mathrm{p}>0.05$; Table S3), so these were considered as one "pelagic plankton" source group. The first two principal component axes of the PCA of the grouper $\delta^{13} \mathrm{C}_{\text {EAAn }}$ values explained $69.2 \%$ of the variation and showed no clear grouping of species or atoll areas (Figure 1; Table S4). The PCA of the primary consumers showed clear separation of the different food source groups, particularly axis one, which explained $68.1 \%$ of the variation, while the second principal component axis explained $21.4 \%$ of the variation (Figure 2A; Table S4). The separation along PC1 indicated three broad groups of primary consumers: 1) pelagic plankton, 2) reef plankton, nocturnal plankton, and coral, and 3) benthic algae and detritus. A third PCA visualised the associations between the groupers and the primary consumers (Figure 2B; Table S4). The first two axes explained $89.4 \%$ of the variation and the groupers were closest in position to the pelagic plankton sources.

Based on the gap statistic and the cluster analysis the primary consumers were split into four source groups, which represented: 1) algae/detritus, 2) coral, 3) reef plankton, and 4) pelagic plankton (Figure 3). When running Bayesian isotope mixing models, sources can be combined a posteriori based on biological knowledge (Phillipset al. 2005; Phillips et al. 2014). Here, after the mixing models had run, the source groups representing coral and algae/detritus were combined into one group named "Reef Benthic".

The mixing models indicated that all four groupers derived the majority (95-99\%) of their food from pelagic production sources in both inner and outer atoll (Figure 4). Median pelagic source reliance was significantly greater in the outer atoll (98-99\%) than in the inner atoll (95-97\%) (Two-sample $t$-test, $t=-5.06, \mathrm{df}=4.53$, $\mathrm{p}=0.005)$. Patterns in pelagic reliance were consistent between atoll areas among the groupers. Of all four 
groupers, Aethaloperca rogaa consistently had the highest median pelagic reliance, followed by Cephalopholis miniata, Anyperodon leucogrammicus and lastly C. argus . Median reliance on benthic reef and reef plankton sources was higher in the inner atoll (1.5-3\% and 1-1.6\% respectively) than in the outer atoll (0.4-1\% and $0.3-0.6 \%$ respectively). Credible intervals were consistently larger for groupers in the inner atoll than in the outer atoll. C. argus and A. leucogrammicus had the largest overall credible intervals.

\section{Discussion}

Primary consumer $\delta{ }^{13} \mathrm{C}$ values of essential amino acids showed good discrimination among clusters broadly representing benthic algae/detritus, coral, reef plankton (diurnal and nocturnal) and pelagic plankton. The proximity of benthic algae and detritus to each other is not surprising. Although the powderblue surgeonfish,Acanthurus leucrosternon, is classified as a herbivore (Robertsonet al. 1979) and the lined bristletooth, Ctenochaetus striatus, is classified as a detritivore (McMahon et al. 2016), much of the material they are feeding on originates from what is referred to as the epilithic algal matrix (Wilson et al. 2003). Consequently, they are not strictly feeding on a single homogenous production source. Diurnal and nocturnal reef plankton and coral were also isotopically similar to each other, perhaps indicative of dinoflagellate origins, while the fusiliers (Caesio varilineataand C. xanthonota) and soldierfish (Myripristis vittata) are likely feeding on localised reef-based plankton that is supported by the same phytoplankton sources (Hamner et al. 1988; Hobson 1991; Alldredge \& King 2009). A novel finding here is that the ${ }^{13}{ }^{13} \mathrm{C}_{\text {EAn }}$ values of the reef plankton and the pelagic plankton primary consumers were distinct from one another. Mackerel scad, Decapterus macarellus, and Indian Ocean squid, Uroteuthis duvauceli, are found in deeper oceanic waters and $U$. duvauceli come to the surface to feed at night (Smith-Vaniz 1986; Islam et al. 2018). Their $\delta{ }^{13} \mathrm{C}_{\mathrm{EAA}}$ values may be a proxy for a pelagic, deep-water vertically migrating plankton community (Hays 2003) that is distinct from the localised reef plankton community comprised predominantly of copepods (Alldredge \& King 2009). Further work on identifying the sources supporting caesionids is the recommended next step for this work.

Pelagic plankton, rather than reef plankton, primarily sustained all groupers. Oceanic atolls, like those in the Maldives, have an enhanced biomass of mesopelagic prey such as lanternfish and euphausiids (Bradbury et al. 1970; Letessier et al. 2016) which migrate to the surface waters to feed at night. Furthermore, particularly in the Indian Ocean, small benthic reef fish larvae are a key component of the ichthyoplankton and an abundant and continuous supply connect the reef-pelagic interface. Small juveniles and adults $(<50$ $\mathrm{mm}$ in length) of these larvae provide $60 \%$ of consumed biomass on reefs, a contribution until now overlooked, and one thought to drive reef productivity (Brandl et al. 2019). The combination of enhanced mesopelagic prey and consistently available cryptobenthic fauna suggests these reefs may be a sink of pelagic energy (Letessier et al. 2016; Brandl et al. 2019). Conversely, on the Great Barrier Reef, open ocean water-column pathways supported only $57 \%$ of reef fish productivity on forereef slopes, however this contribution was expected to be higher on oceanic reefs (Morais \& Bellwood 2019). Currently, little information exists on $\delta$ ${ }^{13} \mathrm{C}_{\mathrm{EAA}}$ incorporation rates or the timeframe that they may represent, however we hypothesize that the predominantly pelagic $\delta{ }^{13} \mathrm{C}_{\mathrm{EAA}}$ values of the groupers is indicative of an atoll-wide food web fuelled by pelagic subsidies.

Even inside the atoll lagoons, groupers were almost exclusively reliant on pelagic production sources. Extensive mixing of oceanic waters renders lagoonal conditions in the Maldives reefs akin to the open ocean (Rogers et al. 2017), contributing to the consistently high pelagic reliance across the atoll. Furthermore, the Maldives are unique in that they lie across the equator and are therefore subject to equatorial currents that bring allochthonous materials to the archipelago from further afield (Sasamal 2007). These findings correlate with the bulk isotope data (Skinner et al. 2019) and previous research that found no difference in coral host and $\operatorname{POM} \delta{ }^{13} \mathrm{C}$ and $\delta{ }^{15} \mathrm{~N}$ between inner and outer reefs in the Maldives (Radice et al. 2019), providing further evidence of a well-mixed system where oceanic nutrients are available throughout. In contrast, several studies have found an increasing reliance of consumers on oceanic nutrients with proximity to the open ocean (Wyatt et al. 2012; Gajdzik et al. 2016). In the Red Sea, foraging by the snapper Lutjanus ehrenbergii was more benthic on shelf reefs and more planktonic on oceanic reefs (as identified by $\delta$ 
${ }^{13} \mathrm{C}_{\mathrm{EAA}}$ values), but it was unclear whether this difference arose from a reliance on different food items in each location or from differing levels of planktonic inputs to the same food webs (McMahon et al. 2016). Similarly, here, while oceanic nutrients are clearly available throughout, it is uncertain whether the groupers are consistently selecting pelagic-derived prey or all the food webs across the atoll are supported by pelagic inputs.

Grouper $\delta{ }^{13} \mathrm{C}_{\text {EAAn }}$ suggest all four species derive their carbon from the same pathways regardless of size. Previous research indicates $\delta{ }^{13} \mathrm{C}_{\mathrm{EAA}}$ values remain consistent across taxa (McMahon et al. 2016) and differing growth rates (Larsen et al. 2015), although the latter study investigated this for the marine diatom, Thalassiosira weissflogii only, so how this varies among upper level consumers is unknown. While growth rate is partly dependent on food availability, pelagic reef fish have higher growth rates as they exploit adjacent pelagic prey (Morais \& Bellwood 2018). A. rogaa, which had the greatest pelagic reliance, also has the highest reported growth rate, while $C$. argus, which had the lowest pelagic reliance, also has the lowest reported growth rate (Mapleston et al. 2009). Although sampling was substantial, future work would benefit from including more samples across all sizes for greater statistical power. However, the lengthy derivatisation process and high cost of processing samples for CSIA meant this was beyond the scope of this study. Although the number of studies utilising $\delta{ }^{13} \mathrm{C}$ of amino acids is increasing, the incorporation rates of AA from diet to consumer are scarcely known; there is substantial variation among amino acids (Bradley et al. 2014; Downs et al. 2014; Whiteman et al. 2018) and how this varies among taxa is uncertain (Whitemanet al. 2019). Consequently, the dietary timeframe represented by these values is unclear.

This is the first study to hypothesise multiple planktonic sources for reefs using $\delta{ }^{13} \mathrm{C}_{\mathrm{EAA}}$ values and distinguish them in a complex food web. In the Red Sea, calanoid copepods have been used to represent pelagic plankton signatures (McMahon et al. 2016), but this is a relatively enclosed, oligotrophic body of water, with limited exchanges with the adjacent Indian Ocean (Racault et al. 2015), yet planktonic primary productivity and $\mathrm{N}_{2}$ fixation differ between open water and nearshore reef settings (Tilstra et al. 2018). Furthermore, POM increases to the South with increased proximity to nutrient-rich Indian Ocean water (Kürten et al. 2016). Consequently, the pelagic plankton signature derived from reef-based calanoid copepods further North (McMahon et al. 2016) may have been similar to that of the nearshore reef plankton of this study. Additional sampling of plankton from the open water and further South may have resulted in a distinct and separate pelagic plankton isotopic signature such as that found here.

As with all emerging technologies, there is still much that is unknown about $\delta^{13} \mathrm{C}_{\mathrm{EAA}}$ data. Firstly, minimal fractionation of EAA stable isotopes between diet and consumer (McMahon et al. 2010) may not be the case. EAAs may not be directly routed from dietary material but instead might be assimilated from symbiotic gut microbes (Newsome et al. 2011). Alternatively, EAAs may undergo extensive catabolism when absorbed by cells lining the gut (Metges 2000). Both of these phenomena would lead to non-zero fractionation factors but are as yet relatively unexplored (Whitemanet al. 2019). Here, despite using a small fractionation factor for the mixing models, a larger standard deviation value was used to provide additional model parameter space $(0.1 \pm 1.0 \%)$ in the absence of accurate fractionation factors. However, if the ${ }^{13} \mathrm{C}_{\mathrm{EAA}}$ fractionation values are similar to that for non-essential amino acids (-0.5 - 2.4 et al. 2015b), the mixing model may have been too constrained to find an appropriate solution. Consequently, this may explain the rigidity and lack of variation in the food source contribution estimates presented here. As CSIA becomes more routine, greater understanding of the mechanisms through which EAAs are integrated by consumers will be required, and is the recommended next step for future work.

Secondly, all the primary consumer samples (with the exception of the pelagic U. duvauceli and D. macarellus ) were derivatised and analysed prior to the pelagic primary consumers and the groupers. The strong pelagic reliance of the groupers may be influenced by differences in $\delta{ }^{13} \mathrm{C}_{\mathrm{EAA}}$ values between studies arising from: 1) derivatising with different batches of reagents, and 2) the calibration settings of the GC/IRMS at different times (Zhang et al. 2012), causing the groupers to be closest isotopically to the pelagic primary consumers run at the same time as them. However, by using consistent laboratory standards and normalising the $\delta$ ${ }^{13} \mathrm{C}_{\mathrm{EAA}}$ data to the mean, values should be comparable between studies (Larsen et al. 2013; Larsen et al. 
2015; McMahon et al. 2015a; Liew et al. 2019), especially when samples were collected in the field at the same time and run on the same GC/IRMS. As such, it is unlikely that the strong pelagic signature arises solely from methodological discrepancies in $\delta^{13} \mathrm{C}_{\mathrm{EAA}}$ values, but future research should focus on how varying lab or GC/IRMS conditions may influence $\delta^{13} \mathrm{C}_{\mathrm{EAA}}$ values and their ecological interpretation. In addition, several grouper samples were collected at a different time to the others. However, they were caught during the same monsoonal season in the same location and no significant differences in values were identified. Furthermore, $\delta{ }^{13} \mathrm{C}_{\mathrm{EAA}}$ values are thought to be robust to seasonal fluctuations (Larsen et al. 2015) and $\delta$ ${ }^{13} \mathrm{C}_{\text {EAAn }}$ values show even less variability (McMahon et al. 2015a).

While fusiliers are classic reef planktivores, due to their highly mobile nature (Russ et al. 2017), they may not have been the most appropriate proxy for localised reef plankton in this context. Moreover, as groupers are typically more reef-associated ambush predators it is uncertain to what degree they would predate on them, perhaps explaining the lack of reliance on reef plankton sources. Sampling of other diurnal planktivores such as balistids (Odonus niger), pomacentrids (Chromis spp) and serranids (Pseudanthias spp), all frequently found in grouper stomach contents (Shpigel \& Fishelson 1989; St John 1999; Dierking et al. 2011; Meyer \& Dierking 2011), is the recommended next step for this work.

While coral reefs worldwide are experiencing unprecedented losses of live coral cover (Hughes et al. 2017), fish productivity on those that rely on pelagic subsidies may be more resilient to coral bleaching than previously thought (Morais \& Bellwood 2019). Groupers are a fundamental component of the Maldivian reef fishery (Sattar et al. 2014) and their exceptionally high pelagic reliance found here suggests that fishery predictions based solely on habitat loss may be misleading (Robinson et al. 2019).

\section{Acknowledgements}

We thank Mohamed Arzan, Shameem Ali and Ali Nasheed for their help with fieldwork. All work was conducted under research permit (OTHR)30-D/INDIV/2016/515 and (OTHR)30-D/INDIV/2018/466 granted by the Republic of the Maldives Ministry of Fisheries and Agriculture. Newcastle University Animal Welfare and Ethical Review Body approved the project (Project ID: 526). Sample analysis funding was provided by NERC LSMSF Grant BRIS/102/0717 and BRIS/125/1418. CS was supported by a Newcastle University SAgE DTA studentship and a cooperative agreement with Banyan Tree.

\section{References}

1.

Alldredge, A.L. \& King, J.M. (2009). Near-surface enrichment of zooplankton over a shallow back reef: implications for coral reef food webs. Coral Reefs , 28, 895-908.

2 .

Arthur, K.E., Kelez, S., Larsen, T., Choy, C.A. \& Popp, B.N. (2014). Tracing the biosynthetic source of essential amino acids in marine turtles using $\delta^{13} \mathrm{C}$ fingerprints. Ecology , 95, 1285-1293.

3.

Bates, D., Maechler, M., Bolker, B. \& Walker, S. (2015). Fitting Linear Mixed-Effects Models Using lme4. Journal of Statistical Software, 67, 1-48.

4.

Bellwood, D.R. (1988). Seasonal changes in the size and composition of the fish yield from reefs around Apo Island, Central Philippines, with notes on methods of yield estimation. Journal of Fish Biology , 32, 881-893.

5 .

Bierwagen, S.L., Heupel, M.R., Chin, A. \& Simpfendorfer, C.A. (2018). Trophodynamics as a Tool for Understanding Coral Reef Ecosystems. Frontiers in Marine Science , 5, 1-13. 
6.

Boecklen, W.J., Yarnes, C.T., Cook, B.A. \& James, A.C. (2011). On the Use of Stable Isotopes in Trophic Ecology. Annual Review of Ecology, Evolution, and Systematics , 42, 411-440.

7.

Bradbury, M., Abbot, D., Bovbjerg, R., Mariscal, R., Fielding, W.C., Barber, R.T. et al. (1970). Studies on the fauna associated with the deep scattering layers in the equatorial Indian Ocean, conducted on R/V TE VEGA during October and November 1964. In: International Symposium on Biological Sound Scattering in the Ocean. (ed. Farquhar, G) Maury Center for Ocean Science, Washington, DC., p. 409-452.

8.

Bradley, C.J., Madigan, D.J., Block, B.A. \& Popp, B.N. (2014). Amino Acid Isotope Incorporation and Enrichment Factors in Pacific Bluefin Tuna, Thunnus orientalis. PLOS ONE , 9, e85818.

9.

Brandl, S.J., Tornabene, L., Goatley, C.H.R., Casey, J.M., Morais, R.A., Côté, I.M. et al. (2019). Demographic dynamics of the smallest marine vertebrates fuel coral reef ecosystem functioning.Science , 364, 1189-1192.

10.

Corr, L.T., Berstan, R. \& Evershed, R.P. (2007). Optimisation of derivatisation procedures for the determination of $\delta 13 \mathrm{C}$ values of amino acids by gas chromatography/combustion/isotope ratio mass spectrometry. Rapid Communications in Mass Spectrometry , 21, 3759-3771.

11.

Dalponti, G., Guariento, R.D. \& Caliman, A. (2018). Hunting high or low: body size drives trophic position among and within marine predators. Marine Ecology Progress Series , 597, 39-46.

12 .

Darwin, C. (1842). The Structure and Distribution of Coral Reefs. Being the first part of the geology of the voyage of the Beagle, under the command of Capt. Fitzroy, R.N. during the years 1832 to 1836, London.

13.

DeNiro, M.J. \& Epstein, S. (1978). Influence of diet on the distribution of carbon isotopes in animals. Geochim. Cosmochim. Acta. , 42, 495-506.

14.

Dierking, J., Williams, I.D. \& Walsh, W.J. (2011). Diet composition and prey selection of the introduced grouper species peacock hind (Cephalopholis argus ) in Hawaii. Fishery Bulletin , 107, 464-476.

15.

Downs, E.E., Popp, B.N. \& Holl, C.M. (2014). Nitrogen isotope fractionation and amino acid turnover rates in the Pacific white shrimpLitopenaeus vannamei . Marine Ecology Progress Series , 516, 239-250.

16.

Farmer, N.A. \& Ault, J.S. (2011). Grouper and snapper movements and habitat use in Dry Tortugas, Florida. Marine Ecology Progress Series , 433, 169-184.

17.

Frisch, A.J., Ireland, M. \& Baker, R. (2014). Trophic ecology of large predatory reef fishes: energy pathways, trophic level, and implications for fisheries in a changing climate. Marine Biology , 161, 61-73. 
18.

Frisch, A.J., Ireland, M., Rizzari, J.R., Lönnstedt, O.M., Magnenat, K.A., Mirbach, C.E. et al. (2016). Reassessing the trophic role of reef sharks as apex predators on coral reefs. Coral Reefs , 35, 459-472.

19.

Gajdzik, L., Parmentier, E., Sturaro, N. \& Frédérich, B. (2016). Trophic specializations of damselfishes are tightly associated with reef habitats and social behaviours. Marine Biology , 163.

20.

Green, A.L., Maypa, A.P., Almany, G.R., Rhodes, K.L., Weeks, R., Abesamis, R.A. et al. (2015). Larval dispersal and movement patterns of coral reef fishes, and implications for marine reserve network design. Biological Reviews , 90, 1215-1247.

21.

Hadwen, W.L., Spears, M. \& Kennard, M.J. (2010). Temporal variability of benthic algal $\delta 13 \mathrm{C}$ signatures influences assessments of carbon flows in stream food webs. Hydrobiologia , 651, 239-251.

22 .

Hamner, W.M., Jones, M.S., Carleton, J.H., Hauri, I.R. \& Williams, D.M. (1988). Zooplankton, planktivorous fish, and water currents on a windward reef face: Great Barrier Reef, Australia. Bulletin of Marine Science, 42, 459-479.

23.

Hays, G.C. (2003). A review of the adaptive significance and ecosystem consequences of zooplankton diel vertical migrations. Springer Netherlands Dordrecht, pp. 163-170.

24.

Hedges, J.I., Baldock, J.A., Gélinas, Y., Lee, C., Peterson, M.L. \& Wakeham, S.G. (2002). The biochemical and elemental compositions of marine plankton: A NMR perspective. Marine Chemistry, 78, 47-63.

25.

Hobson, E.S. (1991). Trophic relationships of fishes specialized to feed on zooplankters above coral reefs. In: The Ecology of Fishes on Coral Reefs (ed. Sale, PF). Academic Press San Diego, USA, pp. 69-95.

26.

Hughes, T.P., Kerry, J.T., Álvarez-Noriega, M., Álvarez-Romero, J.G., Anderson, K.D., Baird, A.H. et al. (2017). Global warming and recurrent mass bleaching of corals. Nature , 543, 373-377.

27.

Islam, R., Hajisamae, S., Pradit, S., Perngmak, P. \& Paul, M. (2018). Feeding habits of two sympatric loliginid squids, Uroteuthis(Photololigo) chinensis (Gray, 1849) and Uroteuthis(Photololigo) duvaucelii (d'Orbigny, 1835), in the lower part of the South China Sea. Molluscan Research , 38, 155-162.

28.

Kassambara, A. \& Mundt, F. (2017). Factoextra: Extract and Visualize the Results of Multivariate Data Analyses. R package version 1.0.5. https://CRAN.R-project.org/package=factoextra.

29.

Kaufman, L. \& Rousseeuw, P.J. (1990). Finding Groups in Data. John Wiley \& Sons, New York.

30. 
Kürten, B., Al-Aidaroos, A.M., Kürten, S., El-Sherbiny, M.M., Devassy, R.P., Struck, U. et al. (2016). Carbon and nitrogen stable isotope ratios of pelagic zooplankton elucidate ecohydrographic features in the oligotrophic Red Sea. Progress in Oceanography , 140, 69-90.

31.

Larsen, T., Bach, L.T., Salvatteci, R., Wang, Y.V., Andersen, N., Ventura, M. et al. (2015). Assessing the potential of amino acid ${ }^{13} \mathrm{C}$ patterns as a carbon source tracer in marine sediments: effects of algal growth conditions and sedimentary diagenesis. Biogeosciences , 12, 4979-4992.

32.

Larsen, T., Taylor, D.L., Leigh, M.B. \& O'Brien, D.M. (2009). Stable isotope fingerprinting: a novel method for identifying plant, fungal, or bacterial origins of amino acids. Ecology , 90, 3526-3535.

33.

Larsen, T., Ventura, M., Andersen, N., O’Brien, D.M., Piatkowski, U. \& McCarthy, M.D. (2013). Tracing Carbon Sources through Aquatic and Terrestrial Food Webs Using Amino Acid Stable Isotope Fingerprinting.PLOS ONE , 8, e73441.

34.

Layman, C.A., Winemiller, K.O., Arrington, D.A. \& Jepsen, D.B. (2005). Body size and trophic position in a diverse tropical food web.Ecology , 89, 2530-2535.

35.

Letessier, T.B., Cox, M.J., Meeuwig, J.J., Boersch-Supan, P.H. \& Brierley, A.S. (2016). Enhanced pelagic biomass around coral atolls. Marine Ecology Progress Series , 546, 271-276.

36.

Liew, J.H., Chua, K.W.J., Arsenault, E.R., Thorp, J.H., Suvarnaraksha, A., Amirrudin, A. et al. (2019). Quantifying terrestrial carbon in freshwater food webs using amino acid isotope analysis: Case study with an endemic cavefish. Methods in Ecology and Evolution, 0.

37.

Maechler, M., Rousseeuw, P., Struyf, A., Hubert, M. \& Hornik, K. (2018). cluster: Cluster Analysis Basics and Extensions. $R$ package version 2.0.7-1.

38.

Mapleston, A., Currey, L.M., Williams, A.J., Pears, R., Simpfendorfer, C.A., Penny, A.L. et al. (2009). Comparative biology of key inter-reefal serranid species on the Great Barrier Reef. In:Project Milestone Report to the Marine and Tropical Sciences Research Facility . Reef and Rainforest Research Centre Limited Cairns, p. 55.

39.

Matley, J.K., Maes, G.E., Devloo-Delva, F., Huerlimann, R., Chua, G., Tobin, A.J. et al. (2018). Integrating complementary methods to improve diet analysis in fishery-targeted species. Ecology and Evolution , 8, 9503-9515.

40.

McCauley, D.J., Young, H.S., Dunbar, R.B., Estes, J.A., Semmens, B.X. \& Michel, F. (2012). Assessing the effects of large mobile predators on ecosystem connectivity. Ecological Applications , 22, 1711-1717.

41. 
McMahon, K.W., Berumen, M.L. \& Thorrold, S.R. (2012). Linking habitat mosaics and connectivity in a coral reef seascape. PNAS , 109, 15372-15376.

42.

McMahon, K.W., Fogel, M.L., Elsdon, T.S. \& Thorrold, S.R. (2010). Carbon isotope fractionation of amino acids in fish muscle reflects biosynthesis and isotopic routing from dietary protein. Journal of Animal Ecology , 79, 1132-1141.

43.

McMahon, K.W., McCarthy, M.D., Sherwood, O.A., Larsen, T. \& Guilderson, T.P. (2015a). Millennial-scale plankton regime shifts in the subtropical North Pacific Ocean. Science, 350, 1530-1533.

44.

McMahon, K.W., Polito, M.J., Abel, S., McCarthy, M.D. \& Thorrold, S.R. (2015b). Carbon and nitrogen isotope fractionation of amino acids in an avian marine predator, the gentoo penguin (Pygoscelis papua).Ecology and evolution , 5, 1278-1290.

45.

McMahon, K.W., Thorrold, S.R., Houghton, L.A. \& Berumen, M.L. (2016). Tracing carbon flow through coral reef food webs using a compound-specific stable isotope approach. Oecologia , 180, 809-821.

46.

Metges, C.C. (2000). Contribution of Microbial Amino Acids to Amino Acid Homeostasis of the Host. The Journal of Nutrition, 130, 1857S-1864S.

47.

Meyer, A.L. \& Dierking, J. (2011). Elevated size and body condition and altered feeding ecology of the grouper Cephalopholis argus in non-native habitats. Marine Ecology Progress Series , 439, 203-212.

48.

Morais, R.A. \& Bellwood, D.R. (2018). Global drivers of reef fish growth. Fish and Fisheries , 19, 1-16.

49.

Morais, R.A. \& Bellwood, D.R. (2019). Pelagic Subsidies Underpin Fish Productivity on a Degraded Coral Reef. Current Biology , 29, 1521-1527.e1526.

50.

Newsome, S.D., Fogel, M.L., Kelly, L. \& del Rio, C.M. (2011). Contributions of direct incorporation from diet and microbial amino acids to protein synthesis in Nile tilapia. Functional Ecology , 25, 1051-1062.

51.

Nguyen, R.T. \& Harvey, H.R. (1997). Protein and amino acid cycling during phytoplankton decomposition in oxic and anoxic waters. Organic Geochemistry, 27, 115-128.

52.

Ou, C., Montaña Carmen, G. \& Winemiller Kirk, O. (2017). Body size-trophic position relationships among fishes of the lower Mekong basin. Royal Society Open Science , 4, 160645.

53.

Phillips, D.L., Inger, R., Bearhop, S., Jackson, A.L., Moore, J.W., Parnell, A.C. et al. (2014). Best practices for use of stable isotope mixing models in food-web studies. Canadian Journal of Zoology, 92, 823-835. 
54.

Phillips, D.L., Newsome, S.D. \& Gregg, J.W. (2005). Combining sources in stable isotope mixing models: alternative methods. Oecologia , 144, 520-527.

55.

R Core Team (2017). R: A language and environment for statistical computing. R Foundation for Statistial Computing Vienna, Austria.

56.

Racault, M.-F., Raitsos, D.E., Berumen, M.L., Brewin, R.J.W., Platt, T., Sathyendranath, S. et al. (2015). Phytoplankton phenology indices in coral reef ecosystems: Application to ocean-color observations in the Red Sea. Remote Sensing of Environment, 160, 222-234.

57.

Radice, V.Z., Hoegh-Guldberg, O., Fry, B., Fox, M.D., Dove, S.G. \& Dorrepaal, E. (2019). Upwelling as the major source of nitrogen for shallow and deep reef-building corals across an oceanic atoll system.Functional Ecology , 33, 1120-1134.

58.

Robertson, D.R., Polunin, N.V.C. \& Leighton, K. (1979). The behavioral ecology of three Indian Ocean surgeonfishes (Acanthurus lineatus ,A . leucosternon and Zebrasoma scopas ): their feeding strategies, and social and mating systems. Env. Biol. Fish. , 4, 125-170.

59.

Robinson, J.P.W., Wilson, S.K., Robinson, J., Gerry, C., Lucas, J., Assan, C. et al. (2019). Productive instability of coral reef fisheries after climate-driven regime shifts. Nature Ecology E Evolution, 3, 183-190.

60.

Rogers, J.S., Monismith, S.G., Fringer, O.B., Koweek, D.A. \& Dunbar, R.B. (2017). A coupled wavehydrodynamic model of an atoll with high friction: Mechanisms for flow, connectivity, and ecological implications. Ocean Modelling , 110, 66-82.

61.

RStudio Team (2012). RStudio: Integrated Development for R. (ed. RStudio, I). Boston, MA.

62.

Russ, G.R., Aller-Rojas, O.D., Rizzari, J.R. \& Alcala, A.C. (2017). Off-reef planktivorous reef fishes respond positively to decadal-scale no-take marine reserve protection and negatively to benthic habitat change. Marine Ecology , 38, e12442.

63.

Sano, M. (1989). Feeding habits of Japanese butterflyfishes (Chaetodontidae). Env. Biol. Fish. , 25, 195-203.

64.

Sasamal, S.K. (2007). Island wake circulation off Maldives during boreal winter, as visualised with MODIS derived chlorophyll-a data and other satellite measurements. International Journal of Remote Sensing , 28, 891-903.

65. 
Sattar, S.A., Wood, E., Islam, F. \& Najeeb, A. (2014). Current status of the reef fisheries of Maldives and recommendations for management. In: Darwin Reef Fish Project. Marine Research Centre/Marine Conservation Society (UK).

66.

Scharf, F.S., Juanes, F. \& Rountree, R.A. (2000). Predator size-prey size relationships of marine fish predators: interspecific variation and effects of ontogeny and body size on trophic-niche breadth. Marine Ecology Progress Series , 208, 229-248.

67.

Shpigel, M. \& Fishelson, L. (1989). Food habits and prey selection of three species of groupers from the genus Cephalopholis(Serranidae: Teleostei). Environmental Biology of Fishes , 24, 67-73.

68.

Skinner, C., Newman, S.P., Mill, A.C., Newton, J. \& Polunin, N.V.C. (2019). Prevalence of pelagic dependence among coral reef predators across an atoll seascape. Journal of Animal Ecology , 88, 1564-1574.

69.

Sluka, R.D. \& Reichenbach, N. (1995). Grouper Density and Diversity at Two Sites in the Republic of Maldives. Atoll Research Bulletin , 438.

70.

Smith-Vaniz, W.F. (1986). Carangidae. In: Smiths' sea fishes.(eds. Smith, MM \& Heemstra, PC). SpringerVerlag Berlin, pp. 638-661.

71.

Smith-Vaniz, W.F. (1995). Carangidae. In: FAO Species Identification Guide for Fishery Purposes. Eastern Central Atlantic.(eds. Fischer, W, Krupp, F, Schneider, W, Sommer, C, Carpenter, KE \& Niem, V). FAO Rome.

72.

St John, J. (1999). Ontogenetic changes in the diet of the coral reef grouper Plectropomus leopardus (Serranidae): patterns in taxa, size and habitat of prey. Mar Ecol Prog Ser , 180, 233-246.

73.

Stock, B.C. \& Semmens, B.X. (2016a). MixSIAR GUI User Manual. Version 3.1. .

74 .

Stock, B.C. \& Semmens, B.X. (2016b). Unifying error structures in commonly used biotracer mixing models. Ecology , 97, 2562-2569.

75.

Tibshirani, R., Walther, G. \& Hastie, T. (2001). Estimating the number of clusters in a data set via the gap statistic. Journal of the Royal Statistical Society: Series B (Statistical Methodology), 63, 411-423.

76.

Tilstra, A., van Hoytema, N., Cardini, U., Bednarz, V.N., Rix, L., Naumann, M.S. et al. (2018). Effects of Water Column Mixing and Stratification on Planktonic Primary Production and Dinitrogen Fixation on a Northern Red Sea Coral Reef. Frontiers in Microbiology , 9.

77. 
Vane, K., Larsen, T., Scholz-Bottcher, B.M., Kopke, B. \& Ekau, W. (2018). Ontogenetic resource utilization and migration reconstruction with $\delta^{13} \mathrm{C}$ values of essential amino acids in the Cynoscion acoupa otolith. Ecology and Evolution, 8, 9859-9869.

78.

Vokhshoori, N.L., Larsen, T. \& McCarthy, M.D. (2014). Reconstructing $\delta^{13}$ C isoscapes of phytoplankton production in a coastal upwelling system with amino acid isotope values of littoral mussels. Marine Ecology Progress Series , 504, 59-72.

79.

Wang, Y.V., Wan, A.H.L., Lock, E.-J., Andersen, N., Winter-Schuh, C. \& Larsen, T. (2018). Know your fish: A novel compound-specific isotope approach for tracing wild and farmed salmon. Food Chemistry , $256,380-389$.

80.

Whiteman, J., Elliott Smith, E., Besser, A. \& Newsome, S. (2019). A Guide to Using Compound-Specific Stable Isotope Analysis to Study the Fates of Molecules in Organisms and Ecosystems. Diversity, 11, 8.

81.

Whiteman, J.P., Kim, S.L., McMahon, K.W., Koch, P.L. \& Newsome, S.D. (2018). Amino acid isotope discrimination factors for a carnivore: physiological insights from leopard sharks and their diet.Oecologia, $188,977-989$.

82.

Wilson, S.K., Bellwood, D.R., Choat, J.H. \& Furnas, M. (2003). Detritus in the epilithic algal matrix and its use by coral reef fishes. Oceanography and marine biology: an annual review , 41, 279-309.

83.

Wyatt, A.S.J., Waite, A.M. \& Humphries, S. (2010). Variability in Isotope Discrimination Factors in Coral Reef Fishes: Implications for Diet and Food Web Reconstruction. PLoS One, 5, e13682.

84.

Wyatt, A.S.J., Waite, A.M. \& Humphries, S. (2012). Stable isotope analysis reveals community-level variation in fish trophodynamics across a fringing coral reef. Coral Reefs , 31, 1029-1044.

85.

Zhang, Y., Tobias, H.J., Sacks, G.L. \& Brenna, J.T. (2012). Calibration and data processing in gas chromatography combustion isotope ratio mass spectrometry. Drug testing and analysis , 4, 912-922. 